\title{
Pengaruh Harga Produk dan Promosi Terhadap Volume Penjualan Batik Pada BT Batik Trusmi Medan
}

\author{
Khamo Waruwu $^{1 *}$, Mella Yunita,Ahmad Yudhira ${ }^{2}$, Desy Tampubolon ${ }^{3}$ \\ 1,2,3 Universitas Cut Nyak Dien Medan Indonesia \\ *email : waruwukhamo.se.mm@gmail.com
}

\begin{abstract}
The work of writing this thesis intends to see how much influence Price has on Sales Volume at BT Batik Trusmi Medan, see how much influence Promotion has on Sales Volume at BT Batik Trusmi Medan and to know the effect of Price and Promotion simultaneously on Sales Volume at BT Batik Trusmi Medan. The research was conducted in a quantitative descriptive manner with multiple regression analysis data with a $95 \%$ confidence level. The results of the study obtained that the tolerance level was $<0.05$, i.e. 0.028 , was declared significant, seeing the Promotion tolerance value was below $<0.05$, i.e. 0.010 was declared significant. While the RSquare value is 0.885 or R2 $\mathrm{x} 100 \%$ of $85.50 \%$, meaning that the independent variable of the study shows an influence on the dependent variable with a value of $85.50 \%$, the remaining $14.50 \%$ is influenced by other factors. The conclusion of the study is that product prices and promotions simultaneously have a significant effect on the sales volume of BT Batik Trusmi Medan.
\end{abstract}

Keywords: Product Price, Promotion, Sales Volume.

\begin{abstract}
Abstrak : Karya penulisan skripsi ini bermaksud untuk melihat seberap besar pengaruh Harga terhadap Volume Penjualan pada BT Batik Trusmi Medan, melihat seberapa besar pengaruh Promosi terhadap Volume Penjualan pada BT Batik Trusmi Medan serta mengetahui pengaruh Harga dan Promosi secara simultan Terhadap Volume Penjualan pada BT Batik Trusmi Medan. Penelitian dilakukan secara deskriptif kuantitatif dengan data analisi regresi berganda tingkat kepercayaan sebesar 95\%. Hasil penelitian diperoleh Nilai batastaraf toleransinya $<0.05$ yaitu 0.028 dinyatakan signifikan, melihat Nilai toleransi Promosi adalah berada dibawah $<0.05$ yaitu 0,010 dinyatakan singnifikan. Sedangkan Nilai $R_{\text {Square }}$ yaitu 0.885 atau $\mathrm{R}^{2}$ x $100 \%$ sebesar $85.50 \%$, artinya variabel bebas penelitian menunjukan pengaruh terhadap variabel terikat dengan nilai $85.50 \%$ selebihnya $14,50 \%$ dipengaruhi oleh faktor-faktor lain. Kesimpulan penelitian adalah secara simultan Harga Produk danPromosi berpengaruh signifikan terhadap Volume Penjualan BT Batik Trusmi Medan.
\end{abstract}

Kata kunci: Harga Produk, Promosi, Volume Penjualan

Copyright (c) 2021 The Authors. This is an open access article under the CC BY-SA 4.0 license (https://creativecommons.org/licenses/by-sa/4.0/)

\section{PENDAHULUAN}

Setiap sektor ekonomi dibutuhkan perhatian dari instansi negeripada industri kecil dan kerajinan (fashion). Sektor industri dan kerajinan (fashion) pada tahun 2016 menyumbang sebesar $18,15 \%$ terhadap pertumbuhan ekonomi nasional dengan potensi penting pada pembangunan sektor industri untuk membantu terciptanya struktur ekonomi yang berkesinambungan dan handal. Keberadaan usaha kecil dan kegiatan pemasarannya mampu menciptakan lapangan pekerjaan bagi masyarakat, berpenghasilan secara individu, tidak terikat dengan lembaga tertentu baik segi waktu ataupun jumlah penghasilan untuk memenuhi 
kebutuhannya. Dalam pemasaran memilki 4 kegiatan yang saling terkait mulai dari ide produk, penetapan harga, pemilihan tempat, dan tentunya kegiatan promosi sebagai upaya pengenalan produk kepada masyarakat luas. Konsep inti pemasaran meluputi:kebutuhan,keinginan dan permintaan;produk (barang,jasa dan gagasan); nilai,biaya dan kepuasan;pertukaran dan transaksi;serta hubungan dan jaringan (Putri, 2017:2).

Kegiatan ini mengarah pada penelitian yang dilakukan yakni variable harga, variable promosi, dan variabel penjualan. Pemasaran adalah suatu sistem total dari kegiatan bisnis yang dirancang untuk mendistribusikan barang-barang yangdapat memuaskan keinginan danmencapai sasaran dantujuan organisasi (Mokalu, 2015:255). Setiap usaha yang memiliki kegiatan produksi dan kegiatan pemasaran tentunya dapat mengetahui dan mengukur seberapa besar pencapain tujuan dengan tingkat penjualan yang diraih. Perkembangan kegiatan usaha mikro khususnya di Kota Medan telah berkembang dan mempunyai harapan yang baik dalam pengembangan Usaha mikro, terutama pengembangan usaha mikro pengrajin batik yang terletak di BT Batik Trusmi Medan yang merupakan salah satu kawasan pengrajin batik terbesar di Kota Medan, tetapi melihat kondisi yang ada dilapangan seperti yang dirasakan oleh pelakumikro dari hasil komunikasi yang dilakukanoleh peneliti terdapat beberapa hambatan-hambatan yang menyebabkan produk batik yang diproduksi belum berkembang jelasnya adalah permasalahan pada harga dan media promosi yang dilakukan belum disesuaikan pada tingkat pendapatan masyarakat kecil, disamping itu juga peneliti melakukan wawancara kepada konsumen, diperoleh jawaban dari konsumen bahwa mereka tidak tertarik membeli produk pengrajin batik di BT Batik Trusmi Medan, dikarenakan harga masih raltif tinggi. Untuk itu perlu dilakukannya suatu pengembangan produk dan penyesuaian harga supaya mudah dipasarkan dan mendapat hasil penjualan sesuai dengan harapan.

Penerapan harga disesuaikan dengan tinggkat konsumen yang menjadi sasaran dengan tujuan pencapaian keuntungan maksimal, penentuan harga disesuaikan dengan kondisi masyarakat dengan penetapan posisi produk sesuai kualitas. Harga merupakan nilai ekonomi yang melekat pada produk yang disesuaikan dengan kualitas agar konsumen atau pembeli mendapatkan produk yang berkualitas. Definisi lain dikemukakan oleh Buchari Alma (2011:169), mengemukakan bahwa harga adalah nilai suatu barang yang dinyatakan dengan uang. Menurut Kotler dan Armstrong (2013:151), harga adalah sejumlah uang yang dibebankan atas suatu barang atau jasa atau jumlah dari nilai uang yang ditukar konsumen atasmanfaat-manfaat karena memiliki atau menggunakan produk atau jasa tersebut. Penentuan harga jual sebaiknya sesuai dengan kemampuan masyarakat tentunya dengan pertimbang beban,pendapatan,pelaku usaha lainnya,dan perubahan kemauan pasar. 
promosi penjualan merupakan pemasukan jangka pendek dalam memotivasi pembelian atau penjualan dari suatu produk, jasa promosi merupakan bagian dalam perkenalan produk, penjualan individu dan berbagai cara yang diinginkan untuk mencapai tujuan promosi dan hasil penjualan. Pengenalan produk sudah tentu memberikan daya tarik sendiri dari konsumen ingin mencoba barang baru seperti produk pengrajin batik di BT Batik Trusmi Medan, menarik perhatian konsumen. Adapun masalah dalam mempromosikan produk yang kurang menarik, diskon yang ditawarkan hanya $10 \%$ dan media online yang tidak dapat memikat calon konsumen karena produk tidak bervariasi. Dengan melakukan promosi dan harga yang ditingkatkan, maka dapat berpangaruh pada hasil penjualan.

Volume penjualan merupakan target yang didapatkan perusahaan dari hasil penjualan produk individu maupun secara keseluruhan yang sudah ditentukan sebelumnya. Volume penjualan baik yang bersifat bayar langsung atau dengan cara mencicilnya dengan perhitungan secara keseluruhan dari total yang didapatkan. Menurut Maya Kanita (2019) dalam skripsinya menjelaskan tentang Volume penjualan merupakan pencapaian penjualan yang dinyatakan secara kuantitatif dari segi fisik atau volume unit suatu produk . Karyawan perusahaan pernah tidak mendapatkan bonus ketika penjualan tidak mencapai dan penjualannya tidak mampu menutupi biaya operasional sehingga batik tersebut harus menggunakan pribadi pemilik untuk membayar tunjangan karyawannya. Seandainya volume penjualan meningkat dan biaya distribusi rendah maka pencapaian laba perusahaan semakin besar dan sebaliknya bila volume penjualan menurun maka pencapaian laba penjualan juga menurun.

Disamping peningkatan harga ada strategi yang dibuat dalam upaya peningkatkan penjualan dengan mengadakan kegiatan bauran promosi yaitu antara lain: Promosi Penjualan (SalesPromotion), Periklanan (Advertising), Penjualan Pribadi (Personal Selling), hubungan masyarakat dan penjualan langsung. Menurut Tjiptono (2015:387) promosi merupakan elemen bauran pemasaran yang berfokus pada upaya menginformasikan,membujuk,dan mengingatkan kembali konsumen akan merekdan produk perusahaan. Berbagai upaya yang dapat dilakukan oleh perusahaan untuk meningkatkan pangsa pasarnya antara lain melatih tenaga pemasaran dan promosi agar dapat diperoleh informasi oleh produsen tentang produk yang dijualnya. Demikian juga dalam praktek usaha mikro, kesuksesan penjualan barang merupakan tujuan besar dari pelaku usaha mikro. Produk yang dihasilkan memerlukan manajemen pemasaran yang 
baik, sehingga tujuan yang diharapkan dapat tercapai dengan tingkat keberhasilan yang memuaskan. Pada uraian masalah dalam pembahasan pendahuluan ini dibutuhkan suatu analisis yang baik untuk mendapatkan kesimpulan dan solusi. Maka dengan ini penulis memilih topik penelitian dengan thema "Pengaruh Harga Produk Dan Promosi Terhadap Volume Penjualan Batik Pada BT Batik Trusmi Medan”.

\section{METODE}

Penelitian ini merupakan penelitian deskriptif statistik. Sampel dalam penelitian ini adalah laporan penjualan, diskon penjulan dan harga yang berlaku pada Batik Trusmi Medan dalam kurun waktu tahun 2019 hingga periode Maret 2021.

Analisis data menggunakan multiple regression analys model (model analisis berganda) baik secara parsial maupun simultan. Model persamaannya adalah sebagai berikut:

$\mathrm{Y}=\mathrm{a}+\mathrm{b} 1 \mathrm{X} 1+\mathrm{b} 2 \mathrm{X} 2+\mathrm{e}$

Keterangan :

$\mathrm{Y} \quad=$ Volume Penjualan

a $\quad=$ Konstanta

$b_{1}, b_{2}=$ Koefisien Regresi

$\mathrm{X} 1=$ Harga Produk

$\mathrm{X} 2=$ Promosi

e $\quad=$ Standard Eror

\section{HASIL DAN PEMBAHASAN}

\section{Analisis Deskriptif}

Dari hasil analisis deskriptif berikut ini menghasilkan data harga, diskon, dan volume penjualan Batik Trusmi Medan sebagai berikut:

Tabel 1. Analisis Deskriptif Descriptive Statistics

\begin{tabular}{l|r|r|r|r|r}
\hline & $\mathbf{N}$ & Minimu m & Maximum & $\begin{array}{c}\text { Mea } \\
\mathbf{n}\end{array}$ & \multicolumn{1}{|c}{ Std. Deviation } \\
\hline Harga & 2 & .00 & 545387193.00 & 188308124.8519 & $\mathbf{1 1 8 0 9 4 0 4 1 . 0 0 8 6 3}$ \\
\hline Diskon & 7 & & & & \\
\hline $\begin{array}{l}\text { Volume } \\
\text { Penjualan }\end{array}$ & 7 & .00 & 3683395.32 & 1388570.4796 & $\mathbf{8 0 0 8 7 0 . 8 9 0 6 1}$ \\
\hline
\end{tabular}

a. Dependent Variable: Volume penjualan

Sumber: Data Penelitian Diolah SPSS, 24.00 (2021) 
Berdasarkan data hasil statistik pada Tabel 1 menunjukkan bahwa berdasarkan Variabel Harga (x1) memiliki mean yaitu188308124.8519 dengan nilai standar deviasi sebesar 118094041.00863. Nilai mean ini memiliki nilai yang lebih besar dari nilai minimum yang ditentukan yaitu 0,00 . Hal ini menunjukkan bahwa Harga yang ditawarkan Batik Trusmi Medan relatif sesuai dengan kemampuan pelanggan namun masih perlu dibenahi sehingga bagi pelanggan tidak terasa berat ketika melakukan pembayaran atas jasa yang diberikan.

Variabel Promosi (x2) memiliki mean yaitu1388570.4796 dengan nilai standar deviasi sebesar800870.89061. Nilai mean ini memiliki nilai yang lebih tinggi dari minimum yang ditentukan yaitu0,00. Hal ini menunjukkan bahwa Promosi pada Batik Trusmi Medan cenderung dapat memuaskan pelanggan yang datang dan melakukan produk batik pada BT Batik Trusmi Medan.

Variabel Volume penjualan (Y) memiliki mean yaitu25295844.2222 dengan nilai standar deviasi sebesar 31587340.90431. Nilai mean ini memiliki nilai yang lebih tinggi dari nilai minimum yang ditentukan yaitu0,00. Hal ini menunjukkan bahwa volume penjualan semakin meningkat namun masih perlu dibenahi sehingga memiliki volume penjualan terpenuhi pada Batik Trusmi Medan.

\section{Asumsi Klasik}

Penjelasannya sebagai berikut :

\section{a. Uji Normalitas}

Untuk melihat apakah uji asumsi klasik memiliki alur yang normal atau tidak maka dapat diamatai seperti hasil gambar dibawah ini:

\section{P-Plot}

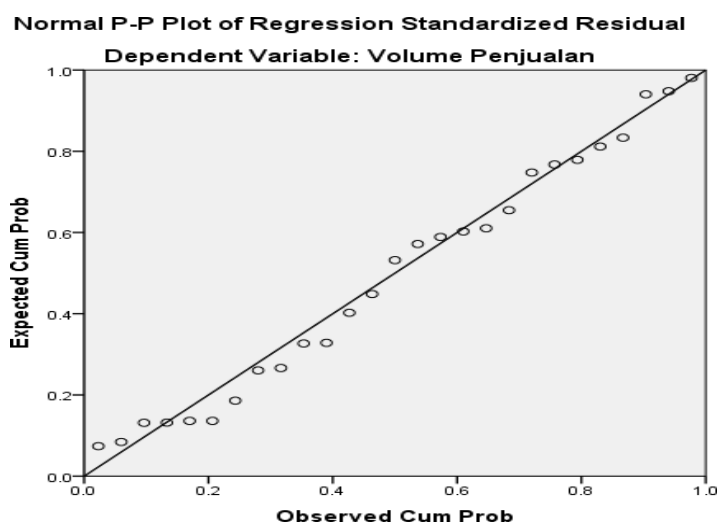

gambar 3. normalitas 
Dari gambar diatas dapat dismpulakan bahwa dat berdistribusi normal dengan melihat Normal Probability Plot, gambar dibawah menunjukkan pola penyebaran data (titik) pada sumbu mendekati diagonal grafik.

\section{b. Uji Multikolinearitas}

Uji multi kolinieritas bermaksud untuk mengelakkan kebiasaan dalam pengambilan kesimpulan mengenai pengaruh pada uji parsial masing-masing variabel independen terhadap variabel dependen (Kurniawan 2014:157). Untuk melihat apa data terjadi multikolinieritas atau tidak bisa dilihat pada tabel berikut ini:

Tabel 2. Uji Multikolinieritas

\begin{tabular}{l|l|r|r}
\hline \multicolumn{2}{c}{} & \multicolumn{2}{c}{ Collinearity Statistics } \\
\cline { 2 - 4 } \multicolumn{2}{l}{ Model } & Toleranc & \multicolumn{1}{c}{ VI } \\
\multicolumn{2}{l|}{} & $\mathrm{e}$ & \multicolumn{1}{c}{ F } \\
\hline 1 & Harga & .179 & $\mathbf{5 . 5 8 5}$ \\
\hline & Promosi & .179 & $\mathbf{5 . 5 8 5}$ \\
\hline
\end{tabular}

Sumber: Data Penelitian Diolah SPSS, 24.00 (2021)

Dari hasil pengolahan data diperoleh nilai tolerance dengan nilai sebesar 0.179>0.10 dengan nilai VIF sebesar 5.585dapat dijelaskan bahwa tidak terjadi multikolinieritas.

\section{c. Uji Heteroskedastisitas}

Dalam perolehan hasil data terlihat pada gambar berikit titik-titik tersebar dengan acak dan tidak membentuk satu pola yang teratur. Titik-titik yang ada menyebar pada atas sumbu $\mathrm{Y}$ dan bawah angka 0 dengan demikian dapat dijelaskan tidak terdapat heterokedastisitas padadata penelitian ini. 


\section{Gambar 4. Uji Heterokedastisitas}

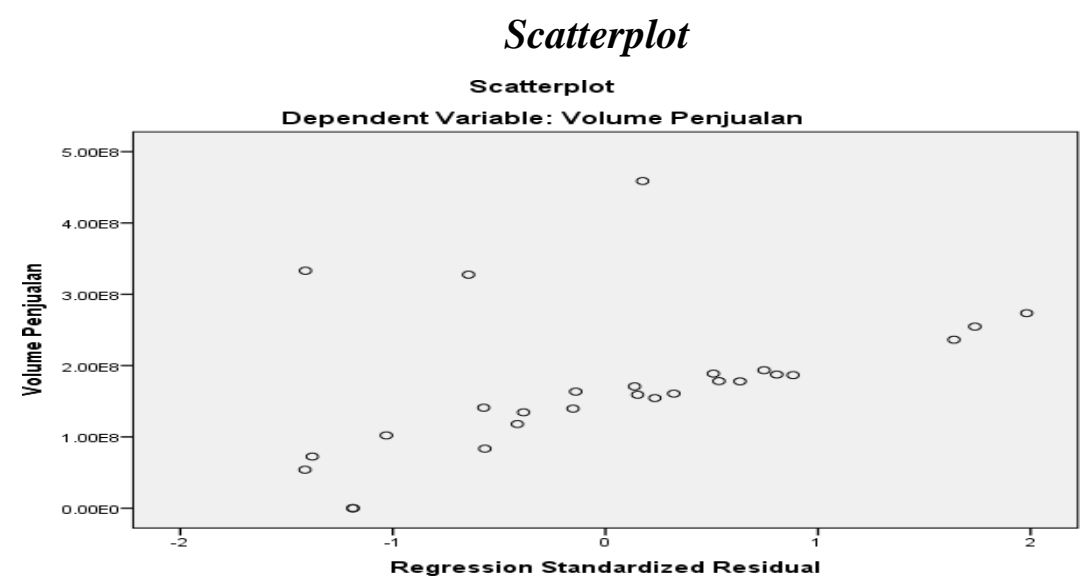

\section{Uji Regresi Berganda}

Dari hasil uji regresi berganda dapat dijelaskan hubungan antara variabel dependen dengan variabel indenpenden seperti pada tabel berikut ini:

Tabel 3. Uji Regresi Berganda

\begin{tabular}{|c|c|c|c|c|c|}
\hline \multirow[t]{2}{*}{ Model } & \multicolumn{2}{|c|}{ Unstandardized Coefficients } & \multirow{2}{*}{$\begin{array}{l}\begin{array}{l}\text { Standardiz } \\
\text { ed }\end{array} \\
\text { Coefficient } \\
\begin{array}{l}\text { s } \\
\\
\multicolumn{1}{c}{\mathrm{Be}} \\
\text { ta }\end{array}\end{array}$} & \multicolumn{2}{|c|}{$\begin{array}{l}\text { Collineari } \\
\text { ty } \\
\text { Statistic } \\
\text { s }\end{array}$} \\
\hline & B & Std. Error & & $\begin{array}{r}\text { Toleranc } \\
\mathrm{e}\end{array}$ & VIF \\
\hline 1 (Constant) & 51428110.740 & 24782680.004 & & & \\
\hline Harga & 63.342 & 27.101 & .430 & .179 & $\mathbf{5 . 5 8 5}$ \\
\hline Promosi & 1.934 & .687 & .517 & .179 & 5.585 \\
\hline
\end{tabular}

\section{Sumber: Data Penelitian Diolah SPSS, 24.00 (2021)}

Hasil regresinya dalam bentuk persamaan yaitu:

$$
\mathrm{Y}=51428110.740+63.342+1.934+\mathrm{e}
$$

Nilai konstanta sebesar 51428110.740(ceteris paribus) variabel komunikasi (X1) dan lingkungan kerja (X2) maka vulume penjualan Batik pada BT Batik Trusmi Medan sebesar 51428110.740 Artinya tanpa Harga Produk yang terjangkaudan menggunakan media promosi yang baik maka, tidak akanmeningkat volume penjulan atau sama sebesar 51428110.740 satuan.

Angka koefisien regresi variabel harga produk 63.342 artinya apabila dilakukan perbaikan harga produk sebesar $1 \%$ (cateris paribus) maka akan meningkatkan volume penjualan batik pada BT Batik Trusmi Medan. Sejumlah yakni 63.34\%. 
Angka koefisien regresi lingkungan kerja adalah 1.934 hal ini berarti jika promosi diperbaiki sebesar 1\% (Cateris Paribus) maka akan meningkatkan volume penjualan batik pada BT Batik Trusmi Medan. Sejumlah yakni 19.34\%.

\section{Pengujian Hipotesis}

a. Uji t

Tabel 4. Uji t (parsial)

\begin{tabular}{l|l|r|r|r|r}
\hline \multicolumn{2}{l|}{} & & & \multicolumn{2}{|c}{ Collinearity Statistics } \\
\cline { 5 - 6 } \multicolumn{2}{c|}{} & T & Sig. & Toleranc & \multicolumn{1}{c}{ VI } \\
\hline $\mathbf{1}$ & & & $\mathrm{e}$ & $\mathbf{F}$ \\
\hline & (Constant) & 2.075 & .049 & & \\
\hline & Harga & 2.337 & .028 & .179 & $\mathbf{5 . 5 8 5}$ \\
\hline & Promosi & $\mathbf{2 . 8 1 5}$ & $\mathbf{. 0 1 0}$ & $\mathbf{. 1 7 9}$ & $\mathbf{5 . 5 8 5}$ \\
\hline
\end{tabular}

a. Dependent Variable: Volumepenjualan

\section{Sumber: Data Penelitian Diolah SPSS, 24.00 (2021)}

Hasil uji t yang ditunjukkan pada tabel 4 untuk variabel harga produk diperoleh taraf signifikan yang bernilai $0.028<0.05$. Hasil penelitian ini menunjukkan bahwaharga produk berpengaruh signifikan terhadap volume penjualan Batik Trusmi Medan.Selanjutnya untuk variabel promosi diperoleh nilai sig $0.010<0.05$ artinyapromosi berpengaruh signifikan terhadap volume penjualan Batik Trusmi Medan.

b. Uji F

Tabel 5 Uji F (Secara Simultan)

ANOVA ${ }^{a}$

\begin{tabular}{l|r|r|r|c|c}
\hline Model & Sum of Squares & D & Mean Square & F & Sig \\
& & f & & & . \\
\hline $\mathbf{1}$ & 309970786053907330. & 2 & 154985393026953600. & 70.67 & $\mathbf{. 0 0}$ \\
Regression & & & & 5 & $\mathbf{0}^{\mathbf{b}}$ \\
\hline Residual & 52630479511540920. & 24 & 2192936646314205. & & \\
\hline \multicolumn{1}{c|}{ Total } & $\mathbf{3 6 2 6 0 1 2 6 5 5 6 5 4 4 8 1 9 0 .}$ & $\mathbf{2 6}$ & & & \\
\hline
\end{tabular}

a. Dependent Variable: Volume penjualan

b. Predictors: (Constant), Harga,Promosi

\section{Sumber: Data Penelitian Diolah SPSS, 24.00 (2021)}

Pada hasil pengolahan data pada tabel 5 di atas mendapatkan nilai signifikan yang bernilai 0,000 sedang taraf yang di tentukan adalah 0.05 , dalam hal ini $(0.000<0.05)$ artinya 
H0 ditolak. Maka dapat disimpulkan bahwa variab harga produk, dan promosi secara simultan berpengaruh secara signifikan terhadap volume penjualan batik Trusmi Medan.

\section{Koefisien Determinasi}

Tabel 6 Model Summary Goodness of Fit $\left(\mathbf{R}^{2}\right)$

\begin{tabular}{l|c|c|c|c|r}
\multicolumn{7}{c}{ Model Summary } \\
\hline \multirow{3}{*}{ Model } & $\mathbf{R}$ & $\mathbf{R}$ & Adjusted & Std. Error of & Durbin- \\
& Squa & $\mathbf{R}$ & the & Watson \\
& & re & Square & Estimate & \\
\hline 1 & .82 & .8 & .843 & $\mathbf{4 6 5 0 5 6 1 0 . 6 3 4 3}$ & .779 \\
& $5^{\mathbf{a}}$ & $\mathbf{5 5}$ & & $\mathbf{0}$ & \\
\hline
\end{tabular}

a. Predictors: (Constant), Promosi, Harga

b. Dependent Variable: Volumepenjualan

\section{Sumber: Data Penelitian Diolah SPSS, 24.00 (2021)}

Dari Nilai $R$ Square hasil pengolahan data diperoleh sebesar 0.825 berarti $82.5 \%$ variabel harga produk, dan promosi mampu menjelaskan pengaruhnya terhadap volume penjualan Batik Trusmi Medan, sedangkan sisanya $17.5 \%$ adalah hal lain yang tidak diteliti pada penelitian ini.

\section{Pembahasan}

Variabel bebas yang pertam dalam penelitian ini Harga memiliki pengaruh dengan nilai perolehan toleransinya $<0,05$ yakni $(0,028<0,05)$, terhadap Volume penjualan Batik Trusmi Medan. Harga merupakan nilai perhitungan dari totalitas suatu barang yang dijual sampai terjadi transaksi.

Bukti berpengaruh variabel bebas ini didukung hasil penelitian yang dilakukan olehAde Irma Novia (2019) Harga dan Kualitas Jaringan Terhadap Minat Beli Perdana Internet Tri (3)adanya pengaruh dengan minat beli Mahasiswa Fakultas Syariah IAIN Ponorogo. Artinya hipotesis dalam penelitian ini variabel bebas terhadap Volume penjualan BT Batik Trusmi Medan dapat diterima dan terbukti kebenarannya.

Variabel bebas yang kedua promosi memiliki pengaruh dengan nilai toleransi< 0,05 yakni $(0,010<0,05)$, artinya Promosi memberikan pengaruh terhadap Volume penjualan BT Batik Trusmi Medan.

Hasil penelitian ini sejalan dengan penelitian yang dilakukan oleh Rizka Amelia Pengaruh Kualitas Produk, Harga dan Citra Merek terhadap keputusan pembelian Kartu Internet Telkomsel(Studi Kasus Pada Mahasiswa IAIN Purwokerto2020/2021) memiliki pengaruh dan signifikan. Simpulkannya adalah hipotesis diterima dan terbukti kebenarannya. 


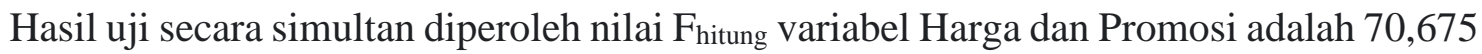
dengan tingkat signifikan 0,000 . Sedangkan, nilai $F_{\text {hitung }}$ pada tingkat signifikan $\alpha=0,05$ adalah 2,960 dimana nilai nilai $\mathrm{F}_{\text {tabel }}$ pada signifikan $\alpha=0,05$ adalah 2,960 (dalam rumus Excel $=\operatorname{TINV}(0.05,3,27))$ dimana nilai $F_{\text {hitung }}>F_{\text {tabel }}(70,675>2,960)$ dan nilai sig $<0,05(0,000<$ 0,05). Dengan demikian, secara simultan terdapat pengaruh yang signifikan antara Harga dan Promosi terhadap Volume penjualan BT Batik Trusmi Medan

Butik harus menyediakan produk dan memberikan layanan yang baik, dan harga yang terjangkau sesuai dengan sasaran konsumen, tempat yang memadai tidak sempit, sehingga calon konsumen memilih batik trusmi medan dibandingkan dengan batik lainnya. Dengan cara seperti itu konsumen dapat bertahan dan lebih setia menggunakan produk yang dijual.

Simpulannya adalah hipotesis antara Harga dan Promosi secara simultan berpengaruh signifikan terhadap Volume penjualan (Y) pada Batik Trusmi Medan, H0 ditolak dan Ha diterima.

\section{SIMPULAN}

Harga produk memiliki pengaruh dan signifikan terhadap volume penjualan dengan hasil uji parsial $\mathrm{X}_{1}$ menunjukkan nilai sig yang bernilai $0.028<0.05$. Promosi memiliki pengaruh dan signfikan terhadap volume penjualan dengan nilai uji parsial $\mathrm{X}_{2}$ dilihat dari nilai signifikansi yang yang diperoleh bernilai $0.010<0.05$. Dari hasil uji Anova secara bersama-samaber pengauruh antara harga variabel bebas dengan variabel terikat dengan nilai toleransi sebesar $0.000<0.05$.

\section{Saran}

1. Dilihat dari pengaruh yang signifikan maka dengan ini peneliti menyarankan agar harga produk Batik Trusmi Medan dapat memilah-milah harga sesuai kemampuan konsumen agar menengah kebawah dapat berbelanja di Batik Trusmi Medan.

2. Untuk promosi dibutuhkan pengembangan agar batik Trusmi Medan tidak familiar pada konsumen tertentu saja diharapkan Batik Trusmi Medan mendapat perhatian dari seluruh lapisan masyarakat yang ada dikota Medan.

3. Agar penelitian ini dapat hasil yang lebih baik, diharapkan kepada peneliti selanjutnya agar menambahkan variabel untuk mendapatkan hasil yang lebih baik. 


\section{DAFTAR RUJUKAN}

Achmad Sani Supriyanto dan Vivin Maharani. 2013. Metode Penelitian Manajemen Sumber Daya Manusia. Malang: UIN- Maliki Press.

Ade Irma Novia(2019) Pengaruh Harga dan Kualitas JaringanTerhadap Minat Beli Perdana Internet Tri (3) Secara parsial harga berpengaruh signifikan terhadap minat beliMahasiswa Fakultas Syariah IAIN Ponorogo. Dikutip Oktober 2021.

Buchari Alma., 2011, Manajemen Pemasaran dan Pemasaran Jasa, Cetakan. Kesembilan, Alfabeth, Bandung

Djaslim, Saladin., 2010. Manajemen Pemasaran, Edisi Pertama, Bandung, Linda Karya Kurniawan, Albert. 2014. Metode Riset Untuk Ekonomi \& Bisnis (Teori, Konsep \& Praktik Penelitian Bisnis (dilengkapi Perhitungan Pengolahan Data dengan IBM SPSS 22.0. Cetakan Ke 1. Bandung: ALFABETA.

Kotler Philip, Amstrong Gary., 2013. Prinsip-prinsip Pemasaran, Edisi ke-12. Penerbit Erlangga.

Maya Kanita (2019).Strategi Promosi Dalam Meningkatkan VolumePenjualan Buku Penerbit Erlangga Di KotaPalangka Raya. $\underline{\text { http://digilib.iain- }}$ palangkaraya.ac.id/1824/1/Maya\%20Kanita-\%201504120405.pdf. Dikutip Oktober 2021.

Mokalu, F. O., \& Tumbel, A. (2015). Pengaruh Harga, Harga Dan Distribusi Terhadap Volume Penjualan Roti Jordan Cv. Minahasa Mantap Perkasa. Jurnal Emba, Iii(1), 254-265.

Putri, R. S. (2017). Pengaruh Promosi Penjualan Dalam Meningkatkan Penjualan Mobil Mitsubishi Pada Pt. Pekan Perkasa Berlian Motor Pekanbaru. Jurnal Valuta, I(2), 298321.

Rizka Amelia. 2020.Pengaruh Kualitas Produk, Harga danCitra Merek terhadap keputusan pembelianKartu Internet Telkomsel(Studi Kasus Pada Mahasiswa IAIN Purwokertohttp://repository.iainpurwokerto.ac.id/9317/1/COVER_BAB\%20I_BAB\% 20V_DAFTAR\%20PUSTAKA.pdf. Dikutip Oktober 2021.

Tjiptono. 2015. Strategi Pemasaran. Edisi 4: Yogyakarta: Andi. 